Article

\title{
Peroxynitrite Sensor Based on a Screen Printed Carbon Electrode Modified with a Poly(2,6-dihydroxynaphthalene) Film
}

\author{
Ioana Silvia Hosu, Diana Constantinescu-Aruxandei, Maria-Luiza Jecu, Florin Oancea and \\ Mihaela Badea Doni *
}

\begin{abstract}
National Institute for Research \& Development in Chemistry and Petrochemistry-ICECHIM, Biotechnology Department, 202 Spl. Independentei, Sector 6, Bucharest, Romania; ioanasilvia.hosu@ed.univ-lille1.fr (I.S.H.); diana.constantinescu@icechim-rezultate.ro (D.C.-A.); jecu.luiza@icechim.ro (M.-L.J.); dir.stiintific@icechim.ro (F.O.)

* Correspondence: mihaela.badea@icechim.ro; Tel.: +40-213-163-063
\end{abstract}

Academic Editor: W. Rudolf Seitz

Received: 24 October 2016; Accepted: 19 November 2016; Published: 23 November 2016

\begin{abstract}
For the first time the electropolymerization of 2,6-dihydroxynaphthalene (2,6-DHN) on a screen printed carbon electrode (SPCE) was investigated and evaluated for peroxynitrite (PON) detection. Cyclic voltammetry was used to electrodeposit the poly(2,6-DHN) on the carbon electrode surface. The surface morphology and structure of poly(2,6-DHN) film were investigated by SEM and FTIR analysis, and the electrochemical features by cyclic voltammetry. The poly(2,6-DHN)/SPCE sensor showed excellent electrocatalytic activity for PON oxidation in alkaline solutions at very low potentials ( $0-100 \mathrm{mV}$ vs. $\mathrm{Ag} / \mathrm{AgCl}$ pseudoreference). An amperometric FIA (flow injection analysis) system based on the developed sensor was optimized for PON measurements and a linear concentration range from 2 to $300 \mu \mathrm{M}$ PON, with a LOD of $0.2 \mu \mathrm{M}$, was achieved. The optimized sensor inserted in the FIA system exhibited good sensitivity $\left(4.12 \mathrm{nA} \cdot \mu \mathrm{M}^{-1}\right)$, selectivity, stability and intra-/inter-electrode reproducibility for PON determination.
\end{abstract}

Keywords: 2,6-dihydroxynaphthalene; electropolymerization; screen printed carbon electrode; peroxynitrite; cyclic voltammetry; amperometry; flow injection analysis; electrocatalysis

\section{Introduction}

Peroxynitrite $\left(\mathrm{ONOO}^{-}\right)$, a very powerful oxidizing agent, is formed in vivo from the nearly diffusion-limited termination reaction between nitric oxide $\left(\mathrm{NO}^{--}\right)$and superoxide $\left(\mathrm{O}_{2}{ }^{-}\right)$. The coexistence of peroxynitrite (PON) precursors in biological tissues used for food, especially in skeletal muscles, implies the PON generation. Since it was reported that peroxynitrite enhances the lipid oxidation [1] and promotes the conversion of oxymyoglobin to metmyoglobin in skeletal muscle [2,3], the PON monitoring and control in the early stages of processing may be important to delay the oxidation processes that affect the quality of meat and meat based products $[4,5]$.

Various methods were developed to detect peroxynitrite. The fluorescent probes method, usually using dihydrodichlorofluorescein (DCFH) and dihydrorhodamine-123 (DHR-123) as the probes [6,7], has been widely employed in the mid-90 $\mathrm{s}$ to monitor peroxynitrite in various biological systems. Lately, new fluorescent probes such as rhodamine B hydrazide [8], HKGreen-1 [9], folic acid [10], boronates [11-13], rhodol [14] for PON detection were described. Very recently, the advances in carbon dots synthesis allowed the development of florescent probes for PON sensing based on carbon dots obtained from tryptophan-doped glucose [15] or from citric acid and urea [16]. Methods based on chemiluminescence [17], UV-Vis spectroscopy [18,19], EPR spectroscopy [20] were also reported. 
The abovementioned methods are indirect methods based on measurements of secondary species and they lack sometimes the sufficient specificity needed for PON detection in biological samples.

During the last decade electrochemistry has become very attractive for sensing of important reactive species present in biological samples due to the possibility of direct, on-line and real-time measurements [21-23]. Amatore et al. [24] studied for the first time the unmediated electrochemical behavior of PON on Pt disk microelectrodes. One of the first electrochemical methods for PON detection in simulated bodily fluid at a bare platinum electrode by linear scan voltammetry was reported by Iwuntze et al. [25]. The process involved the two-electron oxidation of peroxynitrite and a detection limit of $1.6 \times 10^{-7} \mathrm{M}$ was reported. Afterwards, different chemical modifiers were used to modify Pt electrodes. The first one was an electropolymerized manganese tetraaminophthalocyanine film (MnTAPc) used for the determination of PON in alkaline aqueous solution. Bedioui's group showed for the first time a real-time calibration curve of the amperometric determination of stable PON in aqueous solution. MnTAPc film deposited on Pt microelectrodes presented electrocatalytic features on reduction of PON at $-0.5 \mathrm{~V}$ vs. $\mathrm{Ag} / \mathrm{AgCl}$. The sensitivity of the sensor was $14.6 \times 10^{-6} \mu \mathrm{A} \cdot \mu \mathrm{M}^{-1}$ and its detection limit is $5 \times 10^{3} \mu \mathrm{M}$ PON [26]. A PON sensor (wrongly defined as biosensor) has been developed through the preparation of a manganese-[poly-2,5-di-(2-thienyl)-1H-pyrrole)-1-( $p$-benzoic acid)](Mn-pDPB) complex. DPB monomer synthesis and polymerization for the purpose of providing a polymer backbone for complex formation with $\mathrm{Mn}^{2+}$ ion was for the first time reported by Koh et al. [27]. This report claiming that the Mn-pDPB based sensor allows the electroreduction of PON at $+0.2 \mathrm{~V}$ with a sensitivity of $0.157 \pm 0.007 \mu \mathrm{A} \cdot \mu \mathrm{M}^{-1}$ has risen some comments with respect to certain issues such as the neutral $\mathrm{pH}$ of the analyzed PON solutions due to the very short half-life of PON at physiological $\mathrm{pH}$ [28]. Questionable was also the nature of the PON. Koh responded partially to this questions arguing that $\mathrm{PON}$ was introduced via a donor solution of 3-morpholinosydnonimine (SIN-1) which is relatively stable at neutral $\mathrm{pH}$, having a half-life of 14-26 min [29].

A glassy carbon electrode (GCE) modified with electropolymerized film of cyanocobalamin to catalyze the peroxynitrite oxidation at a potential around $+0.75 \mathrm{~V}$ was reported by Wang and Chen [30]. PON was sensitively detected at $\mathrm{pH} 9.2$ by differential pulse voltammetry with the developed poly(cyanocobalamin) sensor in the range 2-300 $\mu \mathrm{M}$ with a detection limit of $0.1 \mu \mathrm{M}$. Since the electroactive polymers such as polypyrrole, polyaniline or poly(3,4-ethylenedioxythiophene) (called PEDOT) become very attractive for electrochemical sensors development [31], a PON sensor using carbon fiber microelectrodes modified with functionalized PEDOT-hemin was reported for the first time by Peteu et al. [32]. These PEDOT-hemin based sensors allowed the electrocatalytic oxidation of $\mathrm{PON}$ at $+0.75 \mathrm{~V}$ vs. $\mathrm{Ag} / \mathrm{AgCl}$, in $\mathrm{pH} 10.5 \mathrm{CAPS}$ buffer solution with a $5 \mathrm{~s}$ response time, $0.2 \mu \mathrm{M}$ limit of detection and an excellent sensitivity of $0.013 \mu \mathrm{A} \cdot \mu \mathrm{M}^{-1}$ [32]. The intrinsic catalytic role of hemin electropolymerized film on carbon electrodes in oxidative detection of PON was also investigated by Peteu et al. [33]. The modified electrode showed an oxidation peak at about $+1.07 \mathrm{~V}$ vs $\mathrm{Ag} / \mathrm{AgCl}$, in the presence of $\mathrm{PON}$ in $\mathrm{pH} 10.5$ buffer solution. In amperometry, at potential of $+0.7 \mathrm{~V}$ vs. $\mathrm{Ag} / \mathrm{AgCl}$, the response of the hemin carbon fiber electrodes was at least four times larger than the bare carbon microelectrode [33]. Based on the results showing improved electrochemical response for some electroactive species at conducting interfaces modified with reduced graphene oxide (rGO) a promising $\mathrm{rGO} /$ hemin modifed glassy carbon interface for the sensitive electrocatalytic detection of peroxynitrite at neutral $\mathrm{pH}$ was proposed [34]. The rGO/ hemin matrix was formed by a facile and environmentally friendly approach based on the reduction of GO with hemin under ultrasonication at room temperature. The $\mathrm{rGO} /$ hemin sensor showed in amperometry, at $\mathrm{E}=+1.1 \mathrm{~V}$ vs. $\mathrm{Ag} / \mathrm{AgCl}$, a very good sensitivity $\left(7.5 \pm 1.5 \mu \mathrm{A} \cdot \mu \mathrm{M}^{-1}\right)$ and low detection limit $\left(5 \times 10^{-3} \mu \mathrm{M}\right)$ for PON generated by SIN-1 [34]. Recently, the electrocatalytic activity of cobalt phthalocyanine tetracarboxylic acid $(\mathrm{CoPc}-\mathrm{COOH})$ loaded on reduced graphene oxide (rGO) films towards PON was investigated [35]. The developed sensor proved to be also very sensitive $\left(11.5 \pm 1 \mu \mathrm{A} \cdot \mu \mathrm{M}^{-1}\right)$ in chronoamperometry at the potential $\mathrm{E}=+1.1 \mathrm{~V}$ vs. $\mathrm{Ag} / \mathrm{AgCl}$. Very recently the Peteu's group reported a hemin-PEDOT functionalized boron-doped diamond microelectrode for PON detection with LOD $=0.01 \mu \mathrm{M}$ [36]. 
Almost all of the reported electrochemical sensors based on the electrocatalytic oxidation of PON are operating at a voltage higher than $+0.7 \mathrm{~V}$ where many other compounds present in the biological samples like meat food are susceptible to electrochemical oxidation. In this work we investigate the electrocatalytic features towards PON of the poly(2,6-dihydroxynaphthalene). The first sensor assembled by the 2,6-dihydroxynaphthalene (2,6-DHN) electro-copolymerisation with 2-(4-aminophenyl)-ethylamine (AP-EA) was done onto Pt electrodes [37]. The resulted film proved to be a very good support for enzyme immobilization with a remarkable rejection of interferences such as ascorbic acid or acetaminophen. Poly(2,6-DHN) electrodeposited on Pt was reported as a very selective amperometric sensor for nitrite determination $(\mathrm{E}=+0.9 \mathrm{~V})$ in meat extracts with $\mathrm{pH} 4.0$ [38]. Herein, the authors observed that poly(2,6-DHN) electropolymerised on carbon electrodes shows catalytic properties on electrooxidation of $\mathrm{PON}$ in alkaline solutions at potentials much lower $(\sim+0.1 \mathrm{~V})$ comparing with the previous mentioned examples. In this paper we investigated the quantification of PON with a cost-effective sensor based on poly(2,6-DHN) electropolymerised on a screen printed carbon electrode (SPCE).

\section{Materials and Methods}

\subsection{Chemicals and Materials}

All chemicals, i.e., 2,6-dihydroxynaphthalene (Aldrich, Steinheim, Germany), $\mathrm{Na}_{2} \mathrm{HPO}_{4} \cdot 2 \mathrm{H}_{2} \mathrm{O}$ (Riedel-de Haën, Seelze, Germany), $\mathrm{NaH}_{2} \mathrm{PO}_{4} \cdot 2 \mathrm{H}_{2} \mathrm{O}$ (Merck), $\mathrm{KCl}$ (Sigma-Aldrich, Darmstadt, Germany), $\mathrm{NaOH}$ (Sigma, Darmstadt, Germany), $\mathrm{NaNO}_{2}$ (Riedel-de Haën, Seelze, Germany), $\mathrm{H}_{2} \mathrm{O}_{2} 30 \%$ (Sigma-Aldrich), $\mathrm{MnO}_{2}$ (Merck, Darmstadt, Germany), $\mathrm{HCl}$ (Merck) and ascorbic acid (Sigma-Aldrich) were used without any further purification. Bidistilled water was used to prepare all solutions. Screen printed carbon electrodes (SPCE, Product code: DRP-110) from DropSens, (Llanera, Asturias, Spain) were used in all electrochemical experiments.

\subsection{Electrochemical Instruments}

The SPCE modification by 2,6-DHN electropolymerisation and all the other electrochemical experiments were performed with a potentiostat/galvanostat $\mu$ AUTOLAB type II (Ecochemie, Amsterdam, The Netherlands). A boxed connector for screen-printed electrodes from Dropsens was used to connect the SPCEs. A single-line flow injection system was set up based on a four-channel peristaltic pump (Minipuls 3 from Gilson, Villiers-le-Bel, France) fitted with tygon tubing $(1.12 \mathrm{~mm}$ id) for the propulsion of the carrier solution, an injection valve with $100 \mu \mathrm{L}$ sample loop (model $7725 \mathrm{i}$ from Rheodyne, Cotati, CA, USA) and a flow-cell for screen printed electrodes (model DRP-FLWCL from Dropsens).

\subsection{PON Synthesis}

Peroxynitrite was synthesized from hydrogen peroxide and sodium nitrite according to a slightly modified method [39]. Briefly, in a $50 \mathrm{~mL}$ beaker containing $10 \mathrm{~mL}$ of $0.6 \mathrm{M} \mathrm{H}_{2} \mathrm{O}_{2}$ prepared in $0.7 \mathrm{M}$ $\mathrm{HCl}$ kept on ice were rapidly added $10 \mathrm{~mL}$ of $0.6 \mathrm{M} \mathrm{NaNO}_{2}$ under vigorous magnetic stirring, followed $1 \mathrm{~s}$ later by $10 \mathrm{~mL}$ of ice cold $3 \mathrm{M} \mathrm{NaOH}$ to quench the reaction. Excess hydrogen peroxide was removed by adding $2 \mathrm{~g}$ of $\mathrm{MnO}_{2}$ flakes. $\mathrm{MnO}_{2}$ was removed by filtration and the obtained alkaline stock solution was aliquoted and kept in the dark at $-20^{\circ} \mathrm{C}$. The peroxynitrite concentration of the stock solution was determined prior to each experiment by reading the absorbance at $302 \mathrm{~nm}$ $\left(\varepsilon=1670 \mathrm{~L} \mathrm{~mol}^{-1} \cdot \mathrm{cm}^{-1}\right)$.

\subsection{Preparation of Poly $(2,6-D H N) / S P C E$}

Poly(2,6-DHN) was electropolymerized on the surface of the carbon working electrode by cyclic voltammetry. The monomer solution consisted of $2 \mathrm{mM} 2,6-\mathrm{DHN}$ prepared in phosphate buffer saline (PBS) $\mathrm{pH}$ 7.4. The SPCEs were washed with bidistilled water before use. $100 \mu \mathrm{L}$ of monomer solution 
were placed on the SPCE in order to cover all three (working, reference and counter) electrodes and the potential was cycled from $-0.2 \mathrm{~V}$ to $+1.2 \mathrm{~V}$ with scan rates of 5,10 and $20 \mathrm{mV} / \mathrm{s}$. After modification, the poly(2,6-DHN)/SPCE sensors were rinsed with water and dried in air. When not in use the sensors were kept in dark, at room temperature.

\subsection{Morphological Analysis (Scanning Electron Microscopy)}

The morphological analysis of modified/unmodified carbon electrodes was carried out with scanning electron microscope (SEM) images. The observations of the sensors surfaces were performed with a FEI-QUANTA 200 at the ICECHIM laboratory (Bucharest, Romania). The SEM images were taken at an accelerating voltage of $25-30 \mathrm{kV}$ using a gaseous secondary electron detector (GSED). The micrographs of the samples were investigated at different magnifications to identify changes on the surface between modified and unmodified carbon electrodes. For each sensor, 4-7 micrographs were performed and the relevant images are presented.

\subsection{Fourier Transform Infrared Analysis}

Fourier transform infrared analysis (FTIR) was applied to evaluate the poly(2,6-DHN) formation on the carbon electrode. The FTIR spectra were acquired using a Tensor 37 FT-IR spectrometer (Bruker, Billerica, MA, USA) equipped with a Golden Gate ATR. All samples were recorded from 4000 to $400 \mathrm{~cm}^{-1}$.

\subsection{Analytical Procedure}

PON determination was performed by Flow Injection Analysis (FIA) amperometry. PON samples with a volume of $100 \mu \mathrm{L}$ were injected via the injection valve in a carrier consisting of PBS with pH 9.0, propelled by the peristaltic pump with a flow rate of $0.38 \mathrm{~mL} / \mathrm{min}$. Potentials such as $0,+50,+75$ and $+100 \mathrm{mV}$ were applied to the poly(2,6-DHN)/SPCE sensor introduced in the flow cell. Each sample was injected in triplicate.

\subsection{Meat Extracts Analysis}

The meat extract was prepared according to an adapted procedure used previously for nitrite determination [40]. $2.5 \mathrm{~g}$ of homogenized meat (veal under the age of 2) achieved from a local store was mixed with $25 \mathrm{~mL}$ of cold 0.1 M PBS pH 9.0. The mixture was vigorously stirred for $30 \mathrm{~min}$ at room temperature and then filtered through paper filter with large pores. Samples of meat extract diluted 10 times with PBS pH 9.0 and spiked with PON at different concentrations were analysed using the optimised FIA system.

\section{Results and Discussion}

\subsection{Electrodeposition of Poly(2,6-DHN)}

The first cycle of the cyclic voltammograms performed for $2 \mathrm{mM}$ 2,6-DHN solution at scan rates of 5,10 and $20 \mathrm{mV} \cdot \mathrm{s}^{-1}$, are characterized by a redox couple around $0 \mathrm{~V}$ and a broad oxidation peak around $+0.4 \mathrm{~V}$ as it can be seen in Figure 1a. In Figure $1 \mathrm{~b}$ one can observe that in the second and subsequent scans, the current of the oxidation peaks sharply decreased, indicating the polymerization process and the film formation. After completing 10 cycles of $\mathrm{CV}$, the resulted poly(2,6-DHN)/SPCE electrodes were washed and dried in air. A dark blue film was formed on the carbon working electrode, as shown in Figure 2.

\subsection{Characterization of Poly (2,6-DHN)/SPCE Sensors by SEM and FTIR Analysis}

The surface morphology of poly(2,6-DHN) film on the SPCE was characterized by SEM comparing with that of the unmodified SPCE. Figure 3 shows that following the electrodeposition process, the rough carbon surface of the working electrode was covered by a thin and reasonably homogeneous 
layer of poly(2,6-DHN). The mini-cracks visible on the unmodified carbon electrode are filled and covered with the polymeric film. The micro-particles present on the surface of the modified SPCEs may be phosphate salts entrapped in the polymer film during the electrodeposition.

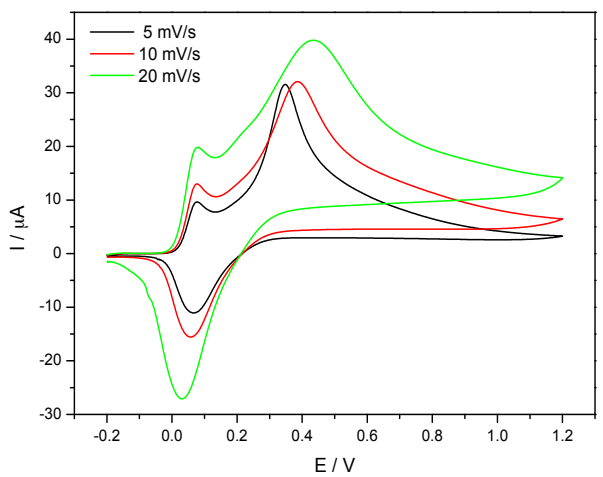

(a)

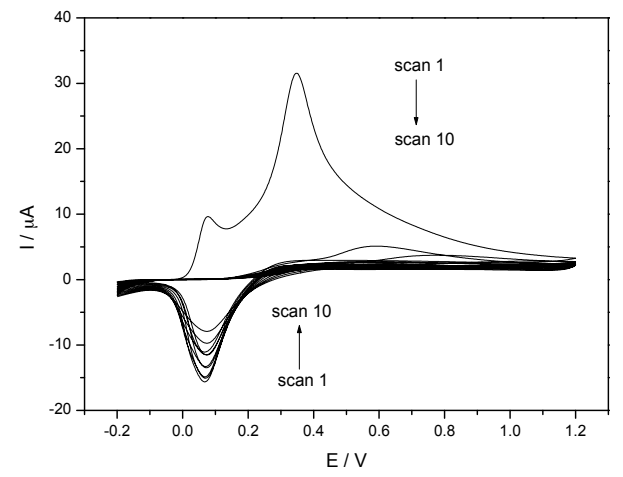

(b)

Figure 1. (a) First CVs of SPCE in $2 \mathrm{mM} 2,6-\mathrm{DHN}$ prepared in $0.1 \mathrm{M}$ PBS pH 7.4 recorded at the scan rates 5,10 and $20 \mathrm{mV} \cdot \mathrm{s}^{-1}$; (b) 10 successive CVs of SPCE in $2 \mathrm{mM} \mathrm{2,6-DHN} \mathrm{at} \mathrm{scan} \mathrm{rate} 5 \mathrm{mV} \cdot \mathrm{s}^{-1}$.

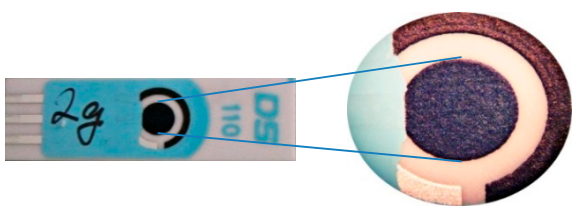

Figure 2. Aspect of the modified SPCE with poly(2,6-DHN).

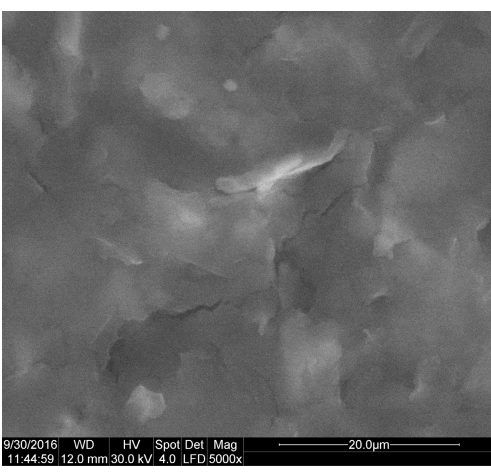

(a)

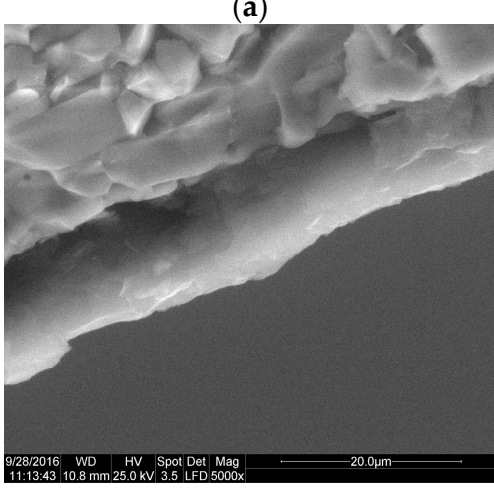

(c)

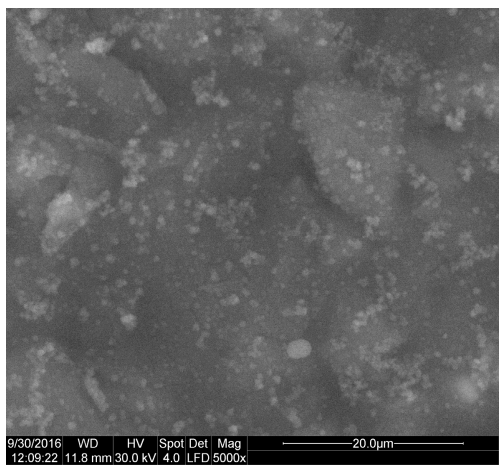

(b)

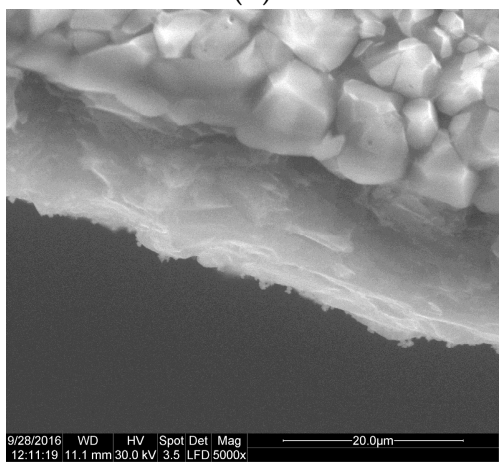

(d)

Figure 3. Frontal $(\mathbf{a}, \mathbf{b})$ and transversal $(\mathbf{c}, \mathbf{d})$ SEM images of the unmodified $(\mathbf{a}, \mathbf{c})$ and modified $(\mathbf{b}, \mathbf{d})$ SPCE. 
The structure of the poly(2,6-DHN) film electrodeposited on the SPCE was investigated also by FTIR-ATR analysis. In Figure 4 the FTIR-ATR spectra of the pure monomer 2,6-DHN and of the poly (2,6-DHN) are presented.

The strong and broad peak at around $3200 \mathrm{~cm}^{-1}$ observed in the spectrum of 2,6-DHN (Figure 4 inset) characteristic to the $\mathrm{O}-\mathrm{H}$ stretching vibration, became broader and shifted to $3400 \mathrm{~cm}^{-1}$ in the spectrum of the poly(2,6-DHN film). This band, together with the band at $1329 \mathrm{~cm}^{-1}$, can be assigned to $\mathrm{O}-\mathrm{H}$ deformation vibration. The band at $1202 \mathrm{~cm}^{-1}$ can be ascribed to the $\mathrm{C}-\mathrm{OH}$ stretching vibration. These results indicate that the $\mathrm{O}-\mathrm{H}$ groups still exist in the poly $(2,6-\mathrm{DHN})$ structure, and the hydroxyl groups did not represent the polymerization sites. Also, the peaks at $1589 \mathrm{~cm}^{-1}$ and $1508 \mathrm{~cm}^{-1}$ characteristic to $C-C$ stretching suggest that the irreversible anodic reaction probably proceeds via $\mathrm{C}-\mathrm{C}$ bond forming polymerization. A similar behavior was reported for the oxidative coupling polymerization of 2,6-DHN in basic water, when amines were used as base [41].

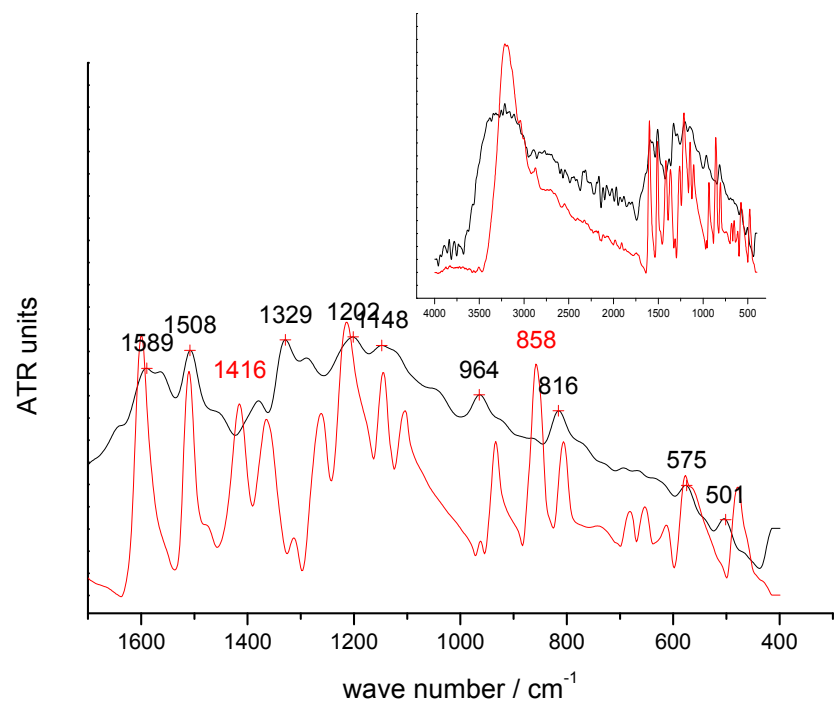

Figure 4. FTIR-ATR spectra for monomer 2,6-DHN (red line) and poly(2,6-DHN)/SPCE (black line).

The suggested structure of the electropolymerized poly(2,6-DHN) and the proposed mechanism for its electrosynthesis are shown in Scheme 1.

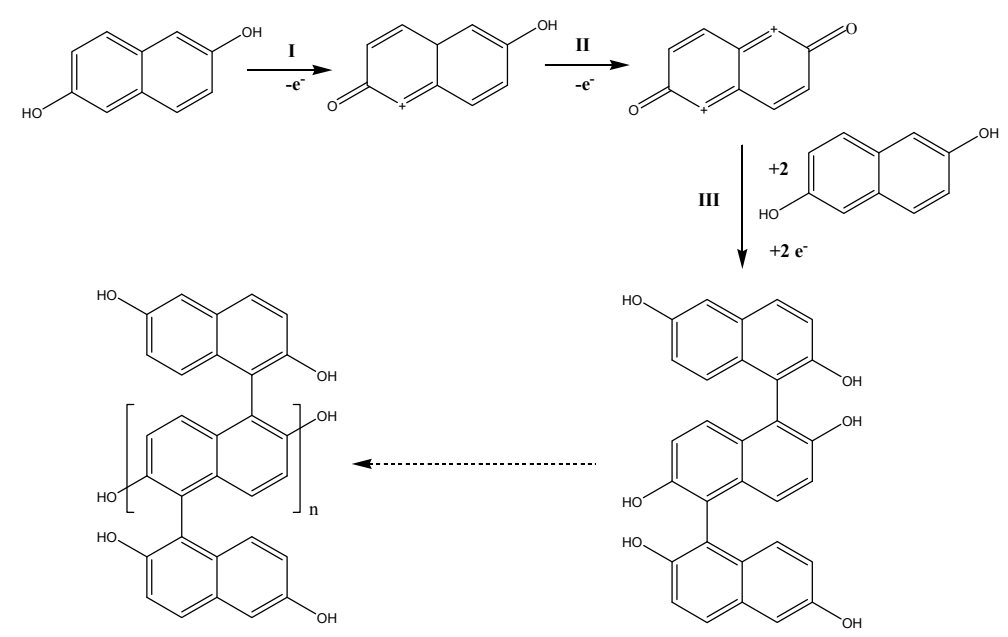

Scheme 1. Suggested electropolymerisation mechanism and structure for poly(2,6-DHN). 
In the first polymerization cycle, the two oxidation peaks are attributed to reactions I and II, and the reduction peak is attributed to reaction III when a trimer is formed. In the next cycle, the available sites for coupling decrease and only one small oxidation peak shifted to more positive potential is observed. With increasing the number of the cycling scans the oxidation peak almost disappears and the number of 2,6-DHN units in the polymer structure increases.

\subsection{Electrochemical Characterization of the Poly(2,6-DHN)/SPCE Sensors}

Figure 5a shows the voltammetric behavior of the unmodified SPCE and of the poly(2,6-DHN)/SPCE in PBS pH 9.0. No redox peaks were observed for the unmodified SPCE, meanwhile a pair of reversible peaks may be observed for the poly(2,6-DHN)/ SPCE. The anodic and cathodic peaks are situated at $\sim+270 \mathrm{mV}$ and $\sim+97 \mathrm{mV}$, respectively. We attribute the anodic peak to the oxidation of the 2,6-DHN units present in the polymer to naphthalene-2,6-dione and the cathodic peak to the reduction back to 2,6-DHN. The dependence of the peak current $\left(\mathrm{I}_{\mathrm{p}}\right)$ on the scan rate $(v)$ is presented in Figure $5 \mathrm{~b}$. For scan rates below $150 \mathrm{mV} \cdot \mathrm{s}^{-1}$, there is a linear relation between $\mathrm{I}_{\mathrm{p}}$ and $v$ characteristic for a surface-immobilized couple. Above $200 \mathrm{mV} \mathrm{s}^{-1}$ the $\mathrm{I}_{\mathrm{pa}}$ reaches a plateau and above $300 \mathrm{mV} \cdot \mathrm{s}^{-1}$ it starts to decrease (data not shown). It seems that at high scan rates the available time window is not large enough to allow the polymer electrooxidation. For the range of the scan rates studied the peak potentials are almost independent on the scan rate and the redox reaction is apparently reversible. A similar behavior for scan rates above $150 \mathrm{mV} \cdot \mathrm{s}^{-1}$ was reported for a catechin film electrodeposited on glassy carbon [42].

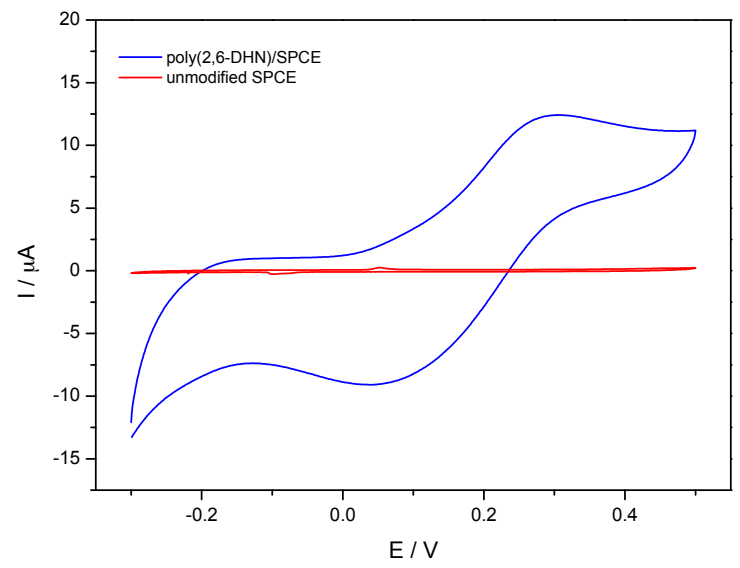

(a)

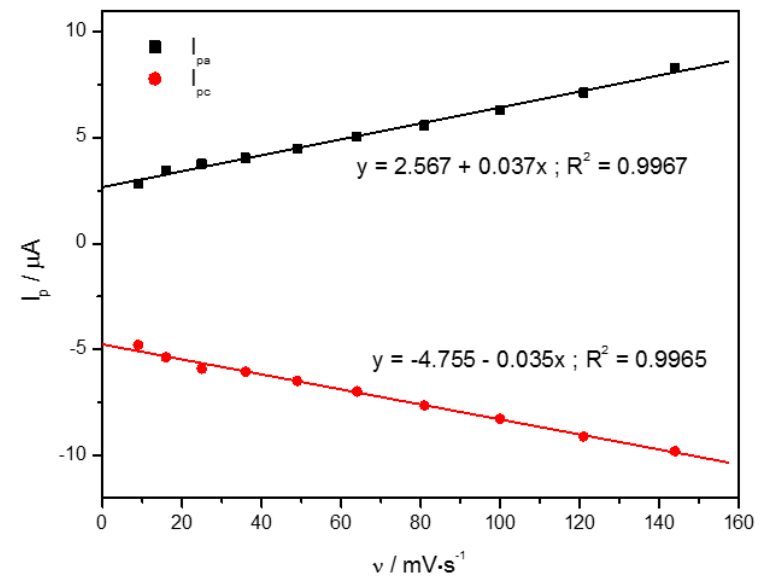

(b)

Figure 5. (a) CVs for poly(2,6-DHN)/SPCE and unmodified SPCE in $0.1 \mathrm{M}$ PBS pH 9.0. Scan rate $100 \mathrm{mV} \cdot \mathrm{s}^{-1}$; potential range: $-0.3 \mathrm{~V}$ to $+0.5 \mathrm{~V}$; sensor modified by electropolymerization of 2,6-DHN with the scan rate $=5 \mathrm{mV} \cdot \mathrm{s}^{-1}$. (b) Dependence of the anodic and cathodic peak currents $\left(\mathrm{I}_{\mathrm{p}}\right)$ on scan rate $(v)$ for poly $(2,6-\mathrm{DHN}) / \mathrm{SPCE}$ in $0.1 \mathrm{M} \mathrm{PBS} \mathrm{pH} 9.0$. Scan rates: $9-144 \mathrm{mV} \cdot \mathrm{s}^{-1}$; sensor modified by electropolymerization of 2,6-DHN with the scan rate $=5 \mathrm{mV} \cdot \mathrm{s}^{-1}$.

Taking into consideration the stability of PON in high alkaline solution, the poly(2,6-DHN)/ SPCEs were characterized in 0.1 M PBS with different $\mathrm{pH}$ between 7.4 and 12 , by cycling the potential from $-0.6 \mathrm{~V}$ to $+0.5 \mathrm{~V}$, with the scan rate $100 \mathrm{mV} \cdot \mathrm{s}^{-1}$. Greatly enhanced peaks, both anodic and cathodic, with the $\mathrm{pH}$ increasing were observed (Figure 6). Also, it was observed that the potential of the peaks is not influenced by $\mathrm{pH}$, indicating that the hydrogen ions are not involved in the electrode reaction. The increasing of the peak currents with $\mathrm{pH}$ suggests that the electrooxidation of the 2,6-DHN units to naphthalene-2,6-dione involves hydroxyl ions. However, it was observed that the high $\mathrm{pH}$ is not favorable for the film stability and integrity. As a compromise, pH 9.0 electrolyte solution was selected for further experiments. 


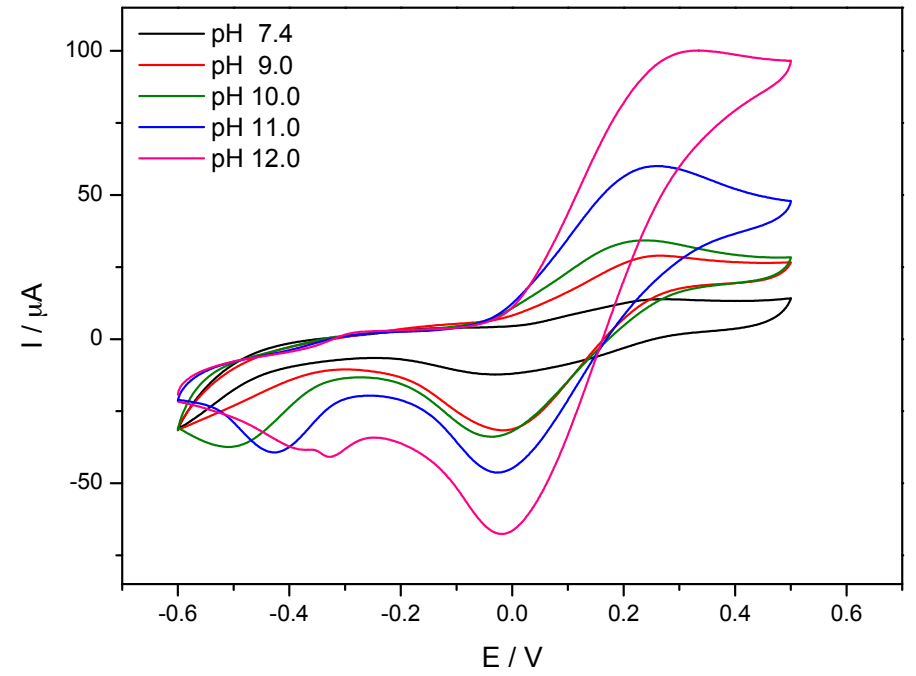

Figure 6. The influence of electrolyte solution $\mathrm{pH}$ on CVs of poly(2,6-DHN)/SPCE. PBS pH: 7.4, 9.0, 9.4 10.0, 11.0, 12.0. Potential range: $-0.5 \mathrm{~V}$ to $+0.5 \mathrm{~V}$; scan rate: $100 \mathrm{mv} \cdot \mathrm{s}^{-1}$; sensor modified by electropolymerization of 2,6-DHN with the scan rate of $20 \mathrm{mV} \cdot \mathrm{s}^{-1}$.

The electrocatalytic behavior of the poly(2,6-DHN)/SPCEs was also evaluated by cyclic voltammetry in the presence and absence of $50 \mu \mathrm{M}$ PON in PBS pH 9.0. The response of the sensor prepared with a scan rate of $5 \mathrm{mV} \cdot \mathrm{s}^{-1}$, presented in Figure 7, shows a significant increase of the anodic and cathodic peaks characteristic to the poly(2,6-DHN) film in the presence of PON. PON induced potentials shift of both anodic and cathodic peak to lower values. One may also observe that in the presence of PON the anodic peak is higher than the cathodic peak. These results indicate that the poly $(2,6-\mathrm{DHN}) / \mathrm{SPCE}$ sensor has electrocatalytic activity towards the PON oxidation. All poly(2,6-DHN)/SPCE sensors showed similar responses, independent on the scanning rate used for electropolymerization of 2,6-DHN.

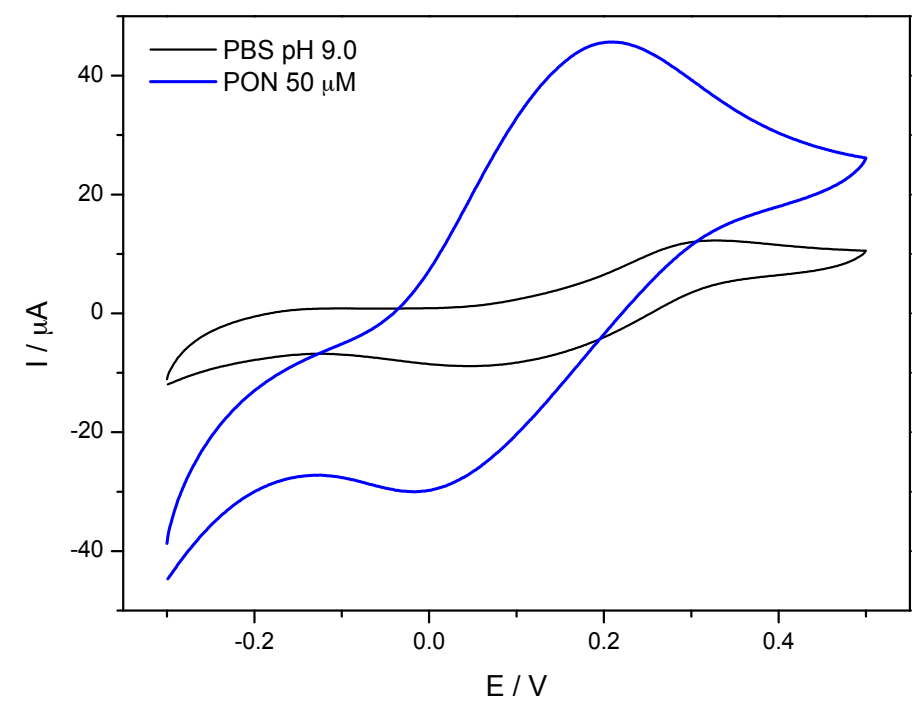

Figure 7. Cyclic voltammograms of poly(2,6-DHN)/SPCE in $0.1 \mathrm{M} \mathrm{PBS} \mathrm{pH} \mathrm{9.0,} \mathrm{in} \mathrm{the} \mathrm{presence} \mathrm{(bue}$ line) and absence (black line) of $50 \mu \mathrm{M}$ PON. Potential range: $-0.3 \mathrm{~V}$ to $+0.5 \mathrm{~V}$; scan rate: $100 \mathrm{mv} \cdot \mathrm{s}^{-1}$. 
In order to get kinetic information the influence of the scan rate was tested for $50 \mu \mathrm{M}$ PON in $0.1 \mathrm{M}$ PBS pH 9.0. Figure 8 shows that both the anodic and cathodic peaks increased linearly with the square root of the scan rate, suggesting a typical behavior of a diffusion controlled reaction [43].

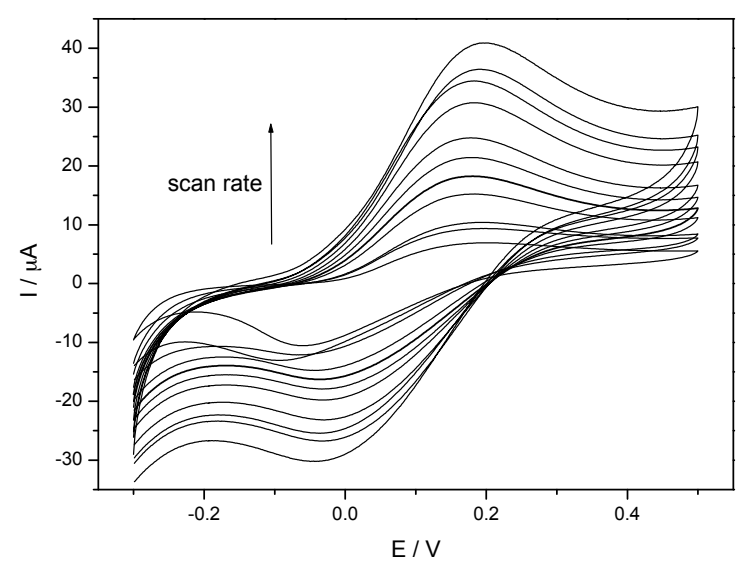

(a)

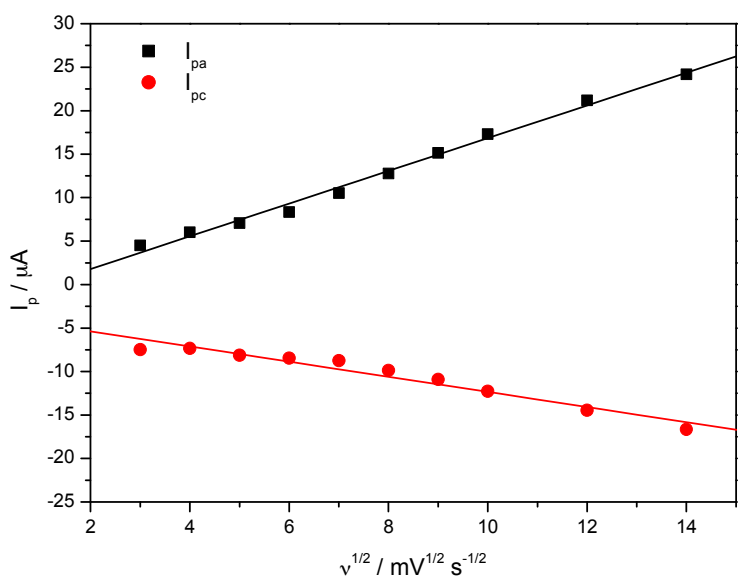

(b)

Figure 8. (a) CVs of poly(2,6-DHN)/SPCE in $0.1 \mathrm{M}$ PBS pH 9.0 containing $50 \mu \mathrm{M}$ PON at scan rates from 9 to $250 \mathrm{mV} \cdot \mathrm{s}^{-1}$. Potential range: $-0.3 \mathrm{~V}$ to $+0.5 \mathrm{~V}$; sensor modified by electropolymerization of 2,6-DHN with the scan rate of $5 \mathrm{mV} \cdot \mathrm{s}^{-1}$. (b) Plot of the anodic and cathodic peak currents vs. square root of scan rate $\left(v^{1 / 2}\right)$

\subsection{Amperometric Detection of PON}

The Flow Injection Analysis (FIA) technique was used for the amperometric detection of PON using the developed poly(2,6-DHN)/SPCE sensor. A very simple single-line FIA system based on injection of $100 \mu \mathrm{L}$ sample in a flow of PBS pH 9.0 pumped with an optimized flow rate of $0.38 \mathrm{~mL} \cdot \mathrm{min}^{-1}$ was used. When the samples reach the electroactive surface of the sensor which is inserted in a special flow cell for screen printed electrodes characteristic FIA peaks are recorded such as shown in Figure 9a. The height of the FIA peaks is proportional to the concentration of PON solution injected. The flow rate is important to be optimized in FIA in order to achieve the highest ratio between the FIA signal and background noise. Flow rates between 0.2 and $0.5 \mathrm{~mL} \cdot \mathrm{min}^{-1}$ were investigated and the optimum was set up at $0.38 \mathrm{~mL} \cdot \mathrm{min}^{-1}$ (data not shown).

In amperometry the choice of the optimum potential applied at the working electrode represents the key parameter in achieving the lowest limit of detection (LOD) and the higher sensitivity. The influence of the applied potential on the height of the FIA signals for different PON concentrations as well as on the background noise was investigated for $\mathrm{E}$ of $0,50,75$ and $100 \mathrm{mV}$ vs. $\mathrm{Ag} / \mathrm{AgCl}$ pseudoreference. In Figure $9 \mathrm{~b}$ the plots representing the dependence of FIA peaks height on PON concentration for the investigated applied potentials are shown. For the potential of $100 \mathrm{mV}$ the highest sensitivity (11.62 nA. $\left.\mu \mathrm{M}^{-1}\right)$ was recorded, but the linear range is limited from $1 \mu \mathrm{M}$ to $50 \mu \mathrm{M}$, and the background is relatively noisy. At $0 \mathrm{~V}$ applied potential the lowest sensitivity was achieved $\left(1.13 \mathrm{nA} \cdot \mu \mathrm{M}^{-1}\right)$ and for potentials of 50 and $75 \mathrm{mV}$ the sensitivity was similar for the PON concentration range up to $100 \mu \mathrm{M}$. The optimum applied potential was found to be $75 \mathrm{mV}$ vs. $\mathrm{Ag} / \mathrm{AgCl}$ pseudoreference due to the broadest concentration range of $\mathrm{PON}(2-300 \mu \mathrm{M})$ and a sensitivity of $4.12 \mathrm{nA} \cdot \mu \mathrm{M}^{-1}$ (Figure 9c). The formula LOD $=3 \sigma_{b} / \mathrm{m}$ was used to calculate the limit of detection, were $\sigma_{\mathrm{b}}$ represents the standard deviation of the background and $\mathrm{m}$ is the slope of the calibration graph. For the optimum applied potential of $75 \mathrm{mV}$ a LOD of $0.2 \mu \mathrm{M}$ PON was achieved. Similarly, a LQD (limit of quantification) of $0.7 \mu \mathrm{M}$ was calculated according to the formula LQD $=10 \sigma_{\mathrm{b}} / \mathrm{m}$. 


\subsection{Selectivity, Reproducibility and Stability of the Poly(2,6-DHN)/SPCE}

In order to test the applicability of the developed sensor for PON detection in real samples, some possibly coexisting interferents in meat extracts, such as ascorbic acid and nitrite, were investigated. Figure $9 \mathrm{~d}$ shows the FIA responses for injection of $1 \mathrm{mM}$ scorbic and $1 \mathrm{mM}$ sodium nitrite solutions compare with that recorded for injection of $50 \mu \mathrm{M}$ PON.

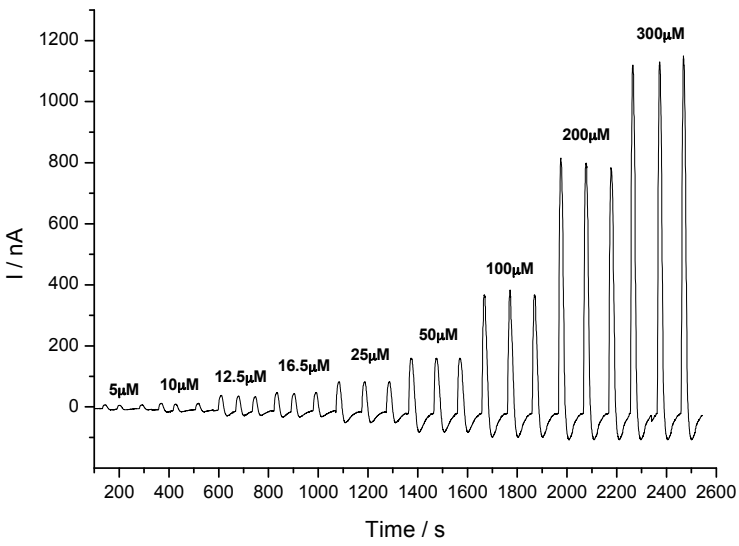

(a)

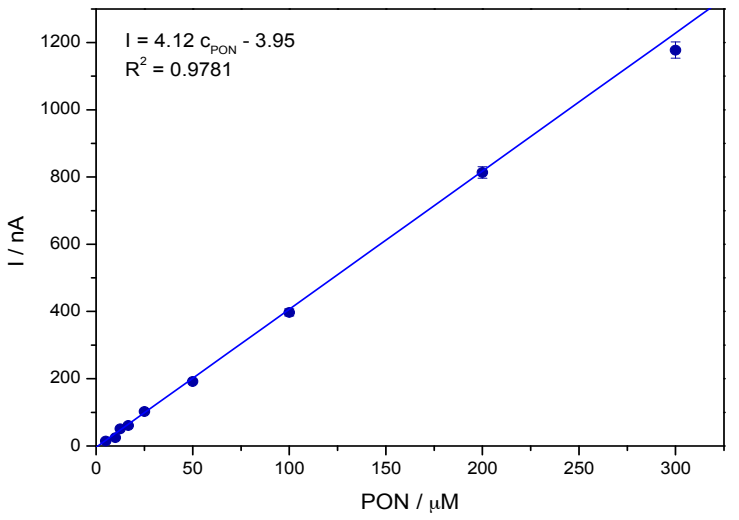

(c)

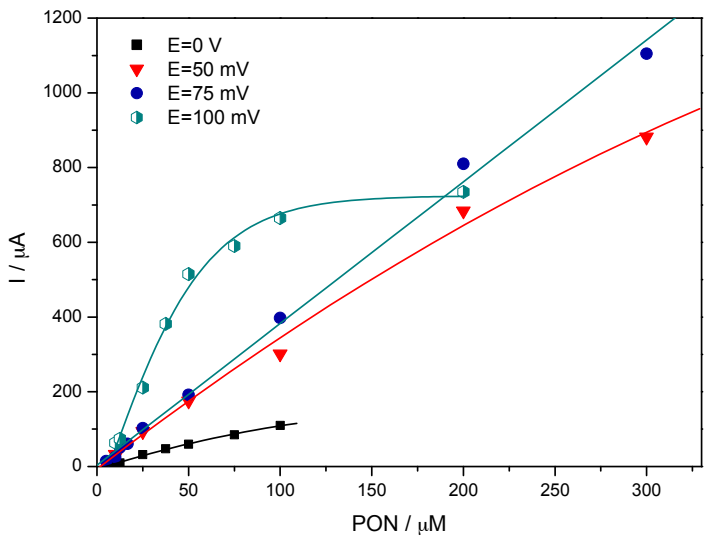

(b)

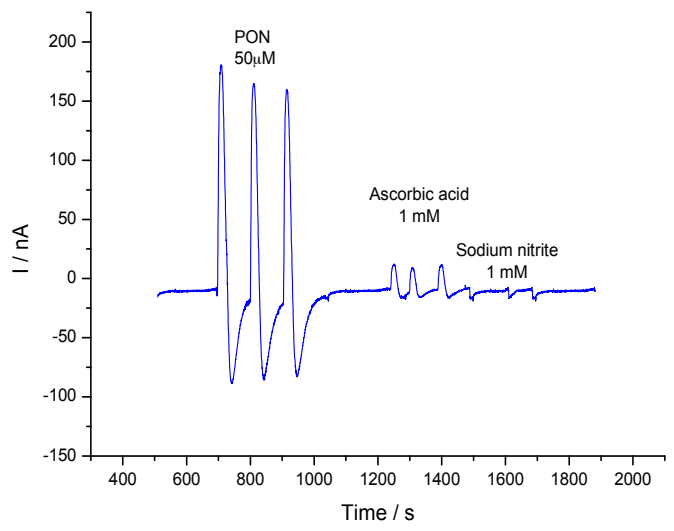

(d)

Figure 9. (a) FIA amperogram for different PON concentration solutions. $E=+75 \mathrm{mV}$; flow rate $=0.38 \mathrm{~mL} \cdot \mathrm{min}^{-1} ;(\mathbf{b})$ Dependence of FIA height on the applied potential for different concentration of PON; flow rate $=0.38 \mathrm{~mL} \cdot \mathrm{min}^{-1}$; (c) Calibration graph for PON determination by FIA amperometry in optimized conditions; $\mathrm{E}=+75 \mathrm{mV}$; flow rate $=0.38 \mathrm{~mL} \cdot \mathrm{min}^{-1}$; (d) FIA signals for PON $50 \mu \mathrm{M}$, ascorbic acid $1 \mathrm{mM}$ and sodium nitrite $0.1 \mathrm{M} ; \mathrm{E}=+75 \mathrm{mV}$; flow rate $=0.38 \mathrm{~mL} \cdot \mathrm{min}^{-1}$.

It is evident that nitrite does not interfere in PON determination and for a 20 times higher concentrated solution of ascorbic acid than that of PON, the interference was low (around $7 \%$ ). The near zero operation voltage of the poly(2,6-DHN)/SPCE succeeds to eliminate the interference of these two important compounds which create major difficulties in PON detection with sensors operating at high potentials. The intra-electrode reproducibility (for the same electrode) investigated for a PON concentration of $50 \mu \mathrm{M}$ resulted in a relative standard deviation (RSD) of $2.3 \%$ for ten consecutive measurements. For the inter-electrode reproducibility study, the RSD determined for six different electrodes was $5.9 \%$ confirming that the fabrication method of the poly(2,6-DHN)/SPCE is highly reproducible.

The operational stability of the developed sensor was examined by successive injections of $50 \mu \mathrm{M}$. It was observed that in the case of the sensor prepared by electropolymerization of 2,6-DHN with the scan rate of $20 \mathrm{mV} \cdot \mathrm{s}^{-1}$, after 10 successive injections the signal decreased with $15 \%$ and the background 
noise increased. The optical and FTIR analysis revealed that the integrity of the poly(2,6-DHN) film was partially affected. Probably, the film electropolymerized at high scan rates does not provide the appropriate features to keep the film integrity in the flowing conditions required for FIA analysis. For the other two electropolymerization scan rates $\left(5\right.$ and $\left.10 \mathrm{mV} \cdot \mathrm{s}^{-1}\right)$, in operational conditions, the amperometric response for PON $50 \mu \mathrm{M}$ retained about $90 \%$ of its initial value after 30 injections. Also, the electrodes stored in air when not in use were able to retain $91 \%-93 \%$ of their original responses after two weeks storage, indicating good stability.

\subsection{PON Recovery in Meat Extract}

For evaluation of the applicability of the developed sensor in real samples, a calibration graph was constructed based on the FIA peaks recorded for samples consisting of meat extract (diluted 10 times with PBS pH.9) spiked with certain amounts of PON in order to reach concentrations between 5 and $200 \mu \mathrm{M}$ (Figure 10). The samples were injected $15 \mathrm{~s}$ after spiking. In Figure 10 it can be observed that the meat extract itself without added PON gave a very small reverse FIA peak. The calibration graph for PON added in meat extract showed a good linearity for the range 5-200 $\mu \mathrm{M}$. The sensitivity of $3.45 \mathrm{nA} \cdot \mu \mathrm{M}^{-1}$ represents $\sim 84 \%$ from the sensitivity recorded for PON determination in PBS pH 9.0, meaning that the meat matrix has a reduced influence on PON determination with the poly(2,6-DHN)/SPCE sensor. The PON recovery in meat extract is $96 \%-99 \%$ for added PON concentration below $50 \mu \mathrm{M}$ and $93 \%-96 \%$ for higher concentration.

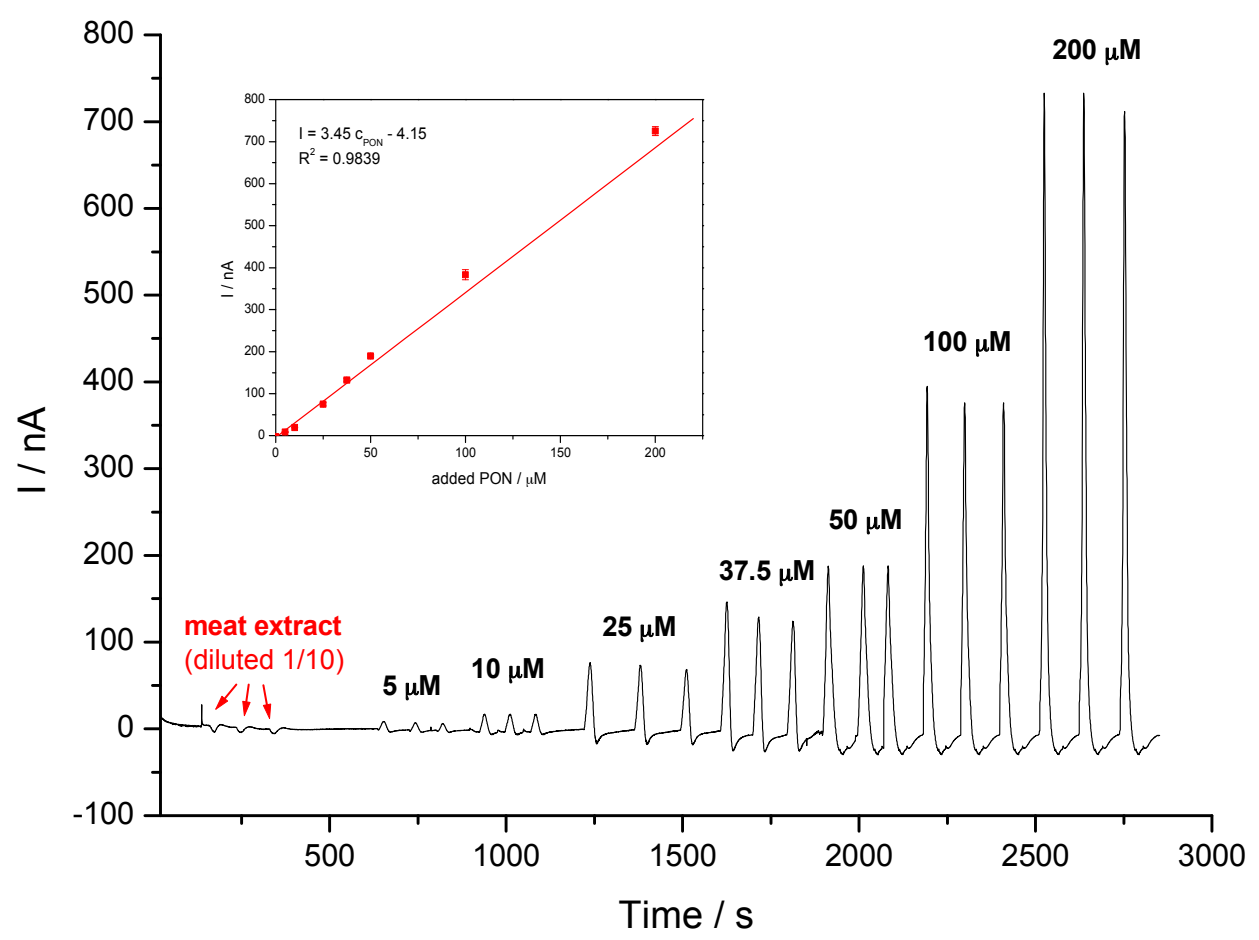

Figure 10. FIA amperogram for PON added in meat extract (diluted $1 / 10$ with PBS pH 9.0). Inside: calibration graph for $\mathrm{PON}$ in meat extract. $\mathrm{E}=+75 \mathrm{mV}$; flow rate $=0.38 \mathrm{~mL} \cdot \mathrm{min}^{-1}$

In Table 1 a comparison between the analytical features of the sensor developed in this work with other similar sensors reported in the literature is presented. 
Table 1. Comparison between the analytical features of different PON sensors.

\begin{tabular}{|c|c|c|c|c|c|}
\hline Mediator/Electrode & Electroanalytical Method & Linear Range $(\mu \mathrm{M})$ & LOD $(\mu \mathrm{M})$ & Sample & Reference \\
\hline Manganese tetraamino-phthalocyanine/Pt microelectrode & Amperometry; Reduction $-\mathrm{E}=-0.5 \mathrm{~V}$ & $16.6-115$ & 5.0 & - & [26] \\
\hline $\begin{array}{l}\text { Manganese-[poly2,5-di-(2-thienyl)-1H-pyrrole)-1-(p-benzoic acid)]/ } \\
\text { Pt microelectrode }\end{array}$ & Amperometry; Reduction-E $=0.2 \mathrm{~V}$ & $0.02-0.05$ & 0.0019 & $\begin{array}{l}\text { Blood plasma; } \\
\text { Cell culture }\end{array}$ & [27] \\
\hline Cyanocobalamin/glassy carbon electrode & Differential pulse voltammetry & $20-300$ & 0.1 & Human serum & [30] \\
\hline hemin-PEDOT/carbon fiber microelectrode & Amperometry; Oxidation-E $=0.75 \mathrm{~V}$ & $1-400$ & 0.2 & - & [32] \\
\hline Reduced graphene oxide/glassy carbon electrode & Amperometry; Oxidation $-\mathrm{E}=1.1 \mathrm{~V}$ & $0.005-0.016$ & 0.005 & - & [34] \\
\hline Poly (2,6-DHN)/screen printed carbon electrode & Amperometry; Oxidation $-\mathrm{E}=0.075 \mathrm{~V}$ & $2-300$ & 0.2 & Meat extract & This work \\
\hline
\end{tabular}




\section{Conclusions}

The electropolymerization of 2,6-dihydroxynapthalene (2,6-DHN) on carbon electrode (screen printed) is reported for the first time. The poly(2,6-DHN)/SPCE demonstrates excellent electrocatalytic activity for PON oxidation in alkaline solutions at very low potential $(0-100 \mathrm{mV}$ vs. $\mathrm{Ag} / \mathrm{AgCl}$ pseudoreference). An amperometric FIA system based on the developed poly(2,6-DHN)/SPCE sensor was optimized for PON measurements. The optimized sensor and FIA system exhibited good selectivity, sensitivity, reproducibility and stability for PON determination, as well as low LOD $(0.2 \mu \mathrm{M}$ $\mathrm{PON})$. All these analytical features of the new carbon electrode modified with poly(2,6-DHN) represent a good premise for a future work related to the integration of this sensor in a smart label for detecting the meat freshness.

Acknowledgments: This work was supported by Romanian National Authority for Scientific Research and Innovation, CNCS-UEFISCDI, Project PN-II-ID-PCE-2011-3-1076, Contract No. 184/2011. The authors are grateful also to Elvira Alexandrescu for SEM images, Violeta Purcar for FTIR measurements and Cristian Petcu for the useful discussions related to the electropolymerisation mechanism.

Author Contributions: M.B.D. and I.S.H conceived and designed the experiments; I.S.H, D.C.-A. and M.B.D. performed the experiments; M.B.D., M.L.J. and F.O. supervised the experiments and analyzed the data; M.B.D. wrote the paper.

Conflicts of Interest: The authors declare no conflict of interest.

\section{References}

1. Brannan, R.G.; Decker, E.A. Peroxynitrite-induced oxidation of lipids: Implications for muscle foods. J. Agric. Food Chem. 2001, 49, 3074-3079. [CrossRef] [PubMed]

2. Connolly, B.; Brannan, R.; Decker, E. Potential of peroxynitrite to alter the color of myoglobin in muscle foods. J. Agric. Food Chem. 2002, 50, 5220-5223. [CrossRef] [PubMed]

3. Connolly, B.; Decker, E. Peroxynitrite induced discoloration of muscle foods. Meat Sci. 2004, 66, 499-505. [CrossRef]

4. Zhang, W.; Xiao, S.; Ahn, D. Protein oxidation: Basic principles and implications for meat quality. Crit. Rev. Food Sci. Nutr. 2013, 53, 1191-1201. [CrossRef] [PubMed]

5. Lindahl, G. Colour stability of steaks from large beef cuts aged under vacuum or high oxygen modified atmosphere. Meat Sci. 2011, 87, 428-435. [CrossRef] [PubMed]

6. Crow, J. Dichlorodihydrofluorescein and dihydrorhodamine 123 are sensitive indicators of peroxynitrite in vitro: Implications for intracellular measurement of reactive nitrogen and oxygen species. Nitric Oxide 1997, 1, 145-157. [CrossRef] [PubMed]

7. Kooy, N.; Royall, J.; Ischiropoulos, H.; Beckman, J. Peroxynitrite-mediated oxidation of dihydrorhodamine-123. Free Radic. Biol. Med. 1994, 16, 149-156. [CrossRef]

8. Yang, X.; Guo, X.; Zhao, Y. Development of a novel rhodamine-type fluorescent probe to determine peroxynitrite. Talanta 2002, 57, 883-890. [PubMed]

9. Yang, D.; Wang, H.; Sun, Z.; Chung, N.; Shen, J. A highly selective fluorescent probe for the detection and imaging of peroxynitrite in living cells. J. Am. Chem. Soc. 2006, 128, 6004-6005. [CrossRef] [PubMed]

10. Huang, J.; Li, D.; Diao, J.; Hou, J.; Yuan, J.; Zou, G. A novel fluorescent method for determination of peroxynitrite using folic acid as a probe. Talanta 2007, 72, 1283-1287. [CrossRef] [PubMed]

11. Sikora, A.; Zielonka, J.; Lopez, M.; Joseph, J.; Kalyanaraman, B. Direct oxidation of boronates by peroxynitrite: Mechanism and implications in fluorescence imaging of peroxynitrite. Free Radic. Biol. Med. 2009, 47, 1401-1407. [CrossRef] [PubMed]

12. Yu, F.; Song, P.; Li, P.; Wang, B.; Han, K. A fluorescent probe directly detect peroxynitrite based on boronate oxidation and its applications for fluorescence imaging in living cells. Analyst 2012, 137, 3740-3749. [CrossRef] [PubMed]

13. Zielonka, J.; Sikora, A.; Hardy, M.; Joseph, J.; Dranka, B.; Kalyanaraman, B. Boronate probes as diagnostic tools for real time monitoring of peroxynitrite and hydroperoxides. Chem. Res. Toxicol. 2012, 25, 1793-1799. [CrossRef] [PubMed] 
14. Peng, T.; Yang, D. Hkgreen-3: A rhodol-based fluorescent probe for peroxynitrite. Org. Lett. 2010, 12, 4932-4935. [CrossRef] [PubMed]

15. Simoes, E.; da Silva, J.; Leitao, J. Carbon dots from tryptophan doped glucose for peroxynitrite sensing. Anal. Chim. Acta 2014, 852, 174-180. [CrossRef] [PubMed]

16. Simoes, E.; Leitao, J.; da Silva, J. Carbon dots prepared from citric acid and urea as fluorescent probes for hypochlorite and peroxynitrite. Microchim. Acta 2016, 183, 1769-1777. [CrossRef]

17. Ribeiro, M.; Dias, A.; Santos, J.; Fernandes, E.; Lima, J.; Zagatto, E. A multipumping flow system for in vitro screening of peroxynitrite scavengers. J. Biomol. Screen. 2007, 12, 875-880. [CrossRef] [PubMed]

18. Li, D.; Wang, L.; Zeng, X.; Zou, G. Spectrophotometric determination of peroxynitrite using o-phenylenediamine as a probe. Anal. Lett. 2004, 37, 2949-2963. [CrossRef]

19. Hou, J.; Yang, J.; Li, K.; Liao, Y.; Yu, K.; Xie, Y.; Yu, X. A highly selective water-soluble optical probe for endogenous peroxynitrite. Chem. Commun. 2014, 50, 9947-9950. [CrossRef] [PubMed]

20. De Menezes, S.; Augusto, O. EPR detection of glutathionyl and protein-tyrosyl radicals during the interaction of peroxynitrite with macrophages (j774). J. Biol. Chem. 2001, 276, 39879-39884. [CrossRef] [PubMed]

21. Borgmann, S. Electrochemical quantification of reactive oxygen and nitrogen: Challenges and opportunities. Anal. Bioanal. Chem. 2009, 394, 95-105. [CrossRef] [PubMed]

22. Amatore, C.; Arbault, S.; Koh, A. Simultaneous detection of reactive oxygen and nitrogen species released by a single macrophage by triple potential-step chronoamperometry. Anal. Chem. 2010, 82, 1411-1419. [CrossRef] [PubMed]

23. Arduini, F.; Micheli, L.; Moscone, D.; Palleschi, G.; Piermarini, S.; Ricci, F.; Volpe, G. Electrochemical biosensors based on nanomodified screen-printed electrodes: Recent applications in clinical analysis. TRAC Trends Anal. Chem. 2016, 79, 114-126. [CrossRef]

24. Amatore, C.; Arbault, S.; Bruce, D.; de Oliveira, P.; Erard, M.; Vuillaume, M. Characterization of the electrochemical oxidation of peroxynitrite: Relevance to oxidative stress bursts measured at the single cell level. Chem. Eur. J. 2001, 7, 4171-4179. [CrossRef]

25. Iwunze, M. Electrooxidation of peroxynitrite in simulated body fluid at platinum electrode. Cell. Mol. Biol. 2004, 50, 759-765. [PubMed]

26. Cortes, J.; Granados, S.; Ordaz, A.; Jimenez, J.; Griveau, S.; Bedioui, F. Electropolymerized manganese tetraaminophthalocyanine thin films onto platinum ultramicroelectrode for the electrochemical detection of peroxynitrite in solution. Electroanalysis 2007, 19, 61-64. [CrossRef]

27. Koh, W.; Son, J.; Choe, E.; Shim, Y. Electrochemical detection of peroxynitrite using a biosensor based on a conducting polymer-manganese ion complex. Anal. Chem. 2010, 82, 10075-10082. [CrossRef] [PubMed]

28. Bedioui, F.; Griveau, S.; Quinton, D. Comment on "Electrochemical detection of peroxynitrite using a biosensor based on a conducting polymer-manganese ion complex". Anal. Chem. 2011, 83, 5463-5464. [CrossRef] [PubMed]

29. Koh, W.; Son, J.; Choe, E.; Shim, Y. Response to the comment on "Electrochemical detection of peroxynitrite using a biosensor based on a conducting polymer-manganese ion complex". Anal. Chem. 2011, 83, 5465-5466. [CrossRef]

30. Wang, Y.; Chen, Z. A novel poly(cyanocobalamin) modified glassy carbon electrode as electrochemical sensor for voltammetric determination of peroxynitrite. Talanta 2010, 82, 534-539. [CrossRef] [PubMed]

31. Lange, U.; Roznyatouskaya, N.; Mirsky, V. Conducting polymers in chemical sensors and arrays. Anal. Chim. Acta 2008, 614, 1-26. [CrossRef] [PubMed]

32. Peteu, S.; Peiris, P.; Gebremichael, E.; Bayachou, M. Nanostructured poly(3,4-ethylenedioxythiophene) -metalloporphyrin films: Improved catalytic detection of peroxynitrite. Biosens. Bioelectron. 2010, 25, 1914-1921. [CrossRef] [PubMed]

33. Peteu, S.; Bose, T.; Bayachou, M. Polymerized hemin as an electrocatalytic platform for peroxynitrite's oxidation and detection. Anal. Chim. Acta 2013, 780, 81-88. [CrossRef] [PubMed]

34. Oprea, R.; Peteu, S.; Subramanian, P.; Qi, W.; Pichonat, E.; Happy, H.; Bayachou, M.; Boukherroub, R.; Szunerits, S. Peroxynitrite activity of hemin-functionalized reduced graphene oxide. Analyst 2013, 138, 4345-4352. [CrossRef] [PubMed] 
35. Hosu, I.S.; Wang, Q.; Vasilescu, A.; Peteu, S.; Raditoiu, V.; Railian, S.; Zaitsev, V.; Turcheniuk, K.; Li, M.; Boukherroub, R.; et al. Cobalt phthalocyanine tetracarboxylic acid modified reduced graphene oxide: A sensitive matrix for the electrocatalytic detection of peroxynitrite and hydrogen peroxide. RSC Adv. 2015, 5, 1474-1484. [CrossRef]

36. Peteu, S.; Whitman, B.; Galligan, J.; Swain, G. Electrochemical detection of peroxynitrite using hemin-pedot functionalized boron-doped diamond microelectrode. Analyst 2016, 141, 1796-1806. [CrossRef] [PubMed]

37. Badea, M.; Curulli, A.; Palleschi, G. Oxidase enzyme immobilisation through electropolymerised films to assemble biosensors for batch and flow injection analysis. Biosens. Bioelectron. 2003, 18, 689-698. [CrossRef]

38. Ocnaru, E.; Arsene, M.; Vasilescu, G.; Doni, M.B. Selective determination of nitrite in cured meat products using a nonconductive polymer film based sensor. Sci. Bull. Ser. F Biotechnol. 2013, 17, 198-201.

39. Robinson, K.; Beckman, J.; Packer, L.; Cadenas, E. Synthesis of peroxynitrite from nitrite and hydrogen peroxide. Methods Enzymol. 2005, 396, 207-214. [PubMed]

40. Badea, M.; Amine, A.; Benzine, M.; Curulli, A.; Moscone, D.; Lupu, A.; Volpe, G.; Palleschi, G. Rapid and selective electrochemical determination of nitrite in cured meat in the presence of ascorbic acid. Microchim. Acta 2004, 147, 51-58. [CrossRef]

41. Tsutsui, Y.; Numao, N.; Suzuki, M. Oxidative coupling polymerization of 2,6-dihydroxynaphthalene in basic water. Polym. J. 2006, 38, 234-239. [CrossRef]

42. Zare, H.; Habibirad, A. Electrochemistry and electrocatalytic activity of catechin film on a glassy carbon electrode toward the oxidation of hydrazine. J. Solid State Electrochem. 2006, 10, 348-359. [CrossRef]

43. Bard, J.B.; Faulkner, R.B. Electrochemical Methods: Fundamentals and Applications, 2nd ed.; Wiley: New York, NY, USA, 2001.

(C) 2016 by the authors; licensee MDPI, Basel, Switzerland. This article is an open access article distributed under the terms and conditions of the Creative Commons Attribution (CC-BY) license (http://creativecommons.org/licenses/by/4.0/). 